\title{
Application of Social Psychology in Supply Chain Management - A Review
}

\author{
"Prashant Singh ${ }^{1}$ \\ Ravi Kumar Jain ${ }^{1}$ \\ Ranjana Sharma ${ }^{2}$
}

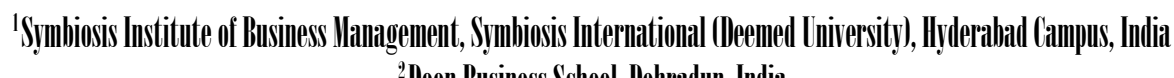
2IDoon Business School, Ielliradun, Indial

\begin{abstract}
Behavioral operations management (BOM) is a rapidly growing field. It relaxes the assumption that "human being is rational" in the decision-making process, considers behavioral and cognitive aspects rooted in psychology to develop models for operations, and processes in production and manufacturing industries. Supply chain management ( $\mathrm{SCM}$ ), being a sub-domain of operations management (OM), has been investigated by combining various social psychology variables and supply chain elements. This article provides a literature review of similar studies. The article focuses on social psychology factors namely: trust, power, attribution theory, social network analysis, compliance, and social preference. This review found that it is imperative for firms to make their supply chains more effective especially when they are operating within competitive business environments. Since a supply chain network consists of various levels with one or more individuals at each level, the interaction between them is mandatory for the efficient functioning of the supply chain. Human behavior is a crucial characteristic to be considered while understanding the supply chain as it can influence the supply chain network's performance and decisions.

Keywords: Behavioral supply chain management, social psychology, human behavior, social network analysis, social preference

JEL: D2, D23
\end{abstract}

In Behavioral operations management (BOM), many cognitive and social psychology theories are applied to several fields of operations management (OM), including Supply Chain Management (SCM) and Inventory Management (Bruccoleri et al., 2014). A supply chain is a system that deals with the movement of products or services from the supplier to customers (or in the reverse direction if the need arises) and includes organizations, people, activities, information, and resources. In today's competitive business environment, an organization needs to make its supply chain efficient enough, i.e., the success of an organization depends on its ability to manage its supply chain effectively. The process of management of multiple relationships across the supply chain is referred to as supply chain management (SCM). The International center for Competitive Excellence defined SCM as "integration of business processes from end-user through original suppliers that provides products, services, and information that add value for customers" (Cooper et al., 1997). The application of these psychology 
theories to SCM is known explicitly as behavioral supply chain management (or behavioral supply management). Doyle et al. (2020) mentioned about the critical role of communication and reflective monitoring in daily supply chain decisions. Also, the organizational culture of a company has an impact on the SCM. A study conducted on Chinese firms found that team-based culture, hierarchy culture, market-oriented culture, and employee perceived behavior have a moderate positively impact on SCM practices (Hong et al., 2020).

Operations Management is a field concerned with designing, improving, and controlling the operations in an organization's production process. Though literature in this area is tremendous, most of the time, the models, developed earlier by researchers, were not eligible to encounter real-world problems. There were many reasons for these gaps, including various assumptions besides many other technical reasons. One of the critical assumptions adopted by many models was that Homo sapiens are always rational beings. However, as Simon (1957) stated, people's rationality is bounded, and hence their capability to solve complex problems is limited. This made researchers relax the assumption of an "always rational human being" and integrate the field of operations management with psychology to capture human cognition and behavior in their models. This gave rise to the field called behavioral operations management (BOM). The field incorporates the concepts of cognitive and social psychology theory and focuses on studying the effect of human cognition and behavior on the operation processes (Bendoly et al., 2006)

Researchers have conducted studies on role of psychological variables in a supply chain network (Schorsch et al., 2017; Melnyk et al., 2014). Several review papers were published on behavioral supply chain management (B-SCM), such as Donohue and Siemsen (2011), and Hewege and Perera (2020). This article focuses on the literature review of research in supply chain incorporating aspects of social psychology, specifically. The article investigates how human interactions among several supply chains can influence the efficiency, performance, and decisions within a supply chain network. The study conducted on Srilanka (Halal) supply chain mentioned how deep-rooted contextual factors such as religious beliefs, cultural rituals, and diverse social institutions on the halal supply chain (Hewege and Perera, 2020).

While research has been done to understand the impact of psychology on supply chains, there is inadequate research on how human interaction within the supply chains affect performance, decisionmaking and the efficiency within said supply networks? This study is divided in various sections, including literature review, methodology, results, discussions, implications, and recommendations for future studies. The literature review explores the role of social psychology in the supply chain based on several factors, including trust, power, attribution theory, social network analysis, and others. The methodology section discusses how the sources and data used in this review were selected, evaluated, and 


\section{Singh et al.}

analyzed. The result and discussion section discusses the essential findings derived from the review. This study's implications are also discussed to show how the study results are appropriate to this field of research. Limitations and future directions are provided to guide future researchers about how they can extend this research.

\section{LITERATURE REVIEW}

\section{Social Psychology and Supply Chain}

Social psychology entails the scientific study of how people's feelings, thoughts, beliefs, goals, and intentions are developed within a social setting through imagined or actual interactions with others. In other words, it examines human behavior as influenced by others or one's environment and the situations under which social feelings and behaviors happen (Kassin et al., 2011). On the other hand, the supply chain is a framework between an organization and its suppliers to yield and distribute particular products or services to the ultimate buyer. This framework encompasses various people, activities, data, and resources (Benton and Maloni, 2005). It also includes a series of steps to get a product or service from its initial state to the final buyer, such as transporting and processing raw materials, transporting finished products, and distributing them to the consumer. The process involves different entities such as manufacturers, vendors, transportation firms, warehouses, distribution facilities, and retailers. Based on social psychology, the behavior and decisions exhibited might rely on the environment under which the entities operate. Now we will discusse the relationship between various social psychological factors and the supply chain, including trust, power, attribution, social network analysis, among others.

\section{-Trust}

The performance of a supply chain strongly depends upon the level of trust among the supply chain partners. Trust and information (or knowledge) sharing is a crucial component for effective supply chain management (Kwon and Suh, 2004). Considering this fact, many researchers have studied how trust and breach of trust influence the relationships of partners in a supply chain. Several authors have defined trust in different ways. Tejpal et al. (2013) mentioned that trust is a relationship in which at least two parties participate, viz. a trustor and a trustee. It is a scenario in which the trustor places himself in a risky situation, and the trustee can take advantage of the trustor's vulnerability (Laeequddin and Sardana, 2010).

Moreover, the lack of trust among the partners can lead to a scenario in which every transactionrelated activity has to be verified, hence entailing the increase in transaction costs (Kwon and Suh, 2004). Sharing of information or knowledge is an essential element in the implementation of a 
successful supply chain. However, information sharing depends upon trust between and among the supply chain partners (Bowersox et al., 2000). It has been highlighted by Cheng et al. (2008), Ghosh and Fedorowicz (2008), and Morgan and Hunt (1994) that trust is positively correlated with knowledge sharing in organizations. Ghosh and Fedorowicz (2008) further mentioned that sharing the information well on time could significantly improve the performance of the supply chain while strengthening the business relationships. Kwon and Suh (2005) have also found a significant positive relationship between the trust level and degree of commitment, where commitment is defined by Morgan and Hunt (1994) as "an exchange partner believing that an ongoing relationship with another is so important as to warrant maximum efforts at maintaining it; that is, the committed party believes the relationship endures indefinitely". Kwon and Suh (2005) have further mentioned that the partner's unpredictable behaviour and information sharing strongly influence the level of trust. Laeequddin and Sardana (2010) studied the factors that can break trust in a supplier-customer relationship using a case study approach. These factors can be knowledge of trustee's characteristics and the possible future outcomes of their relationship, the level of risk for being vulnerable, and the level of risk tolerance, i.e., the extent to which one can bear the risk. When the vulnerability is within the threshold level of risk tolerance, trust can be maintained without breakdown. On the other hand, when the loss due to lack of knowledge is beyond the risk tolerance limit, the trust can be broken. Similarly, Hill et al. (2009) demonstrated the direct relationship between a buyer's unethical behavior and the supplier's trust level.

\section{-Power}

Power is defined as a party's ability to enforce its will on the other party (Emerson, 1962). Power is an essential component in supply chain relationships (Reimann and Ketchen, 2017). It can claim the higher share of value available in the exchange between two firms (Crook and Combs, 2007). Many researchers (Nyaga et al., 2013; Pulles et al., 2014) have argued, based on social exchange theory, that the use of power can damage the relationship between firms. Cheng et al. (2008) also suggested that since power has a negative impact on inter-organizational trust, the supply chain members should respect each other to maintain trust.

Maloni and Benton (2000) found that the power plays a vital role in the supply chain. They suggested that influences of power on the buyer-supplier relationship and subsequent effects of this relationship upon supply chain performance expose the potential of power as a tool to promote the chain's integration and empower higher levels of performance; they extended their research to supplier satisfaction (Benton and Maloni, 2005). Supplier satisfaction is a feeling of equity with the supply chain relationship no matter what power imbalances exist between the buyer-seller dyad (Benton and Maloni, 2005). They found that a power-driven relationship between buyer and supplier has a 


\section{Singh et al.}

significant and positive relationship with performance and supplier satisfaction.

Zhao et al. (2008) studied the relationship between customer power and manufacturer's relationship commitment. Customer power can be defined as a customer's ability to regulate a manufacturer's decisions in a supply chain (Goodman and Dion, 2001). They further mentioned the five power sources, viz. expert power, referent power, legitimate power, reward power, and coercive power. Relationship commitment (RC) in a supply chain can be defined as the supply chain partners' attitude about developing and maintaining a stable, long-lasting mutual relationship (Anderson and Weitz, 1992; Moore, 1998). Relationship commitment (RC) has been further classified into two categories, viz. normative and instrumental (Brown et al., 1995). Normative RC is based on trust, mutual commitment, and knowledge sharing (La Londe and Cooper, 1989), whereas instrumental RC is based on compliance (Brown et al., 1995). The authors carried out an empirical study by using the data from manufacturing companies in China. It was found that expert power, referent power, and reward power enhance the manufacturer's normative RC. On the other hand, coercive power and reward power increase the instrumental RC. They suggested that culture could also play a significant role in determining the relationship between a power type and RC. This was because some of these results were contrary to a similar study conducted by Brown et al. (1995) in the United States.

Ireland and Webb (2007) studied the effect of power and trust on cultural competitiveness within the strategic supply chain. Hult et al. (2002) have defined supply chain cultural competitiveness as the extent to which chains are susceptible to find and fill the gaps between what is desired by the market and what is currently offered. Ireland and Webb (2007) argued that an appropriate balance of trust and power could result in cultural competitiveness in a strategic supply chain. Organizations need to reduce the uncertainties of actions based upon power so that the appropriate balance between trust and power can be achieved.

\section{-Attribution}

Attribution is the process by which individuals attribute the causes of behavior and events. The development of models to explain these processes is called attribution theory (Kassin et al., 2011). According to the attribution theory, attribution is a three-step process. Firstly, the behavior is observed or perceived, then the intentions are assessed, and then that behavior is attributed to an internal or external cause (Weiner, 1992). Attribution theory dimensions include locus of causality, controllability, and stability (Weiner, 1986). These dimensions have also been described in a buyer-supplier context. The locus of causality refers to the buyer's evaluation of the supplier's responsibility for the event. Controllability implies the extent to which the circumstances are avoidable. Stability determines whether the buyer perceives the underlying causes as temporary or permanent (Mir et al., 2017). An extension 
of attribution theory also includes incident severity, which refers to the degree to which a negative incident has caused an impact on an individual.

Hartmann and Moeller (2014) incorporated attribution theory while studying chain liability in a multitier supply chain. It is a process by which customers hold firms responsible for their upstream partners' unsustainable behavior and practices (Hartmann and Moeller, 2014). The authors tested eight hypotheses to determine if customers attribute more responsibility to a firm for unsustainable supplier behavior, utilizing four vignette-based survey experiments. These hypotheses included $\left(H_{1}\right)$ the cause is company failure rather than unavoidable circumstances, $\left(\mathrm{H}_{2}\right)$ the incident occurs at the firm's internal manufacturing sites rather than external suppliers' manufacturing sites, $\left(\mathrm{H}_{3}\right)$ organizational distance between the firm and the supplier is low, $\left(\mathrm{H}_{4}\right)$ the firm is large, $\left(\mathrm{H}_{5}\right)$ the strategic importance of product is great, $\left(\mathrm{H}_{6}\right)$ the incident was caused by the supplier company rather than an individual actor within the company, $\left(\mathrm{H}_{7}\right)$ it has no environmental management system in place, and $\left(\mathrm{H}_{8}\right)$ the outcomes of this behavior are severe. Authors found support for $\left(\mathrm{H}_{1}\right),\left(\mathrm{H}_{6}\right)$ and $\left(\mathrm{H}_{8}\right)$. In other words, the chain liability effect increases if an unsustainable practice (1) results from supplier's behavior rather than unavoidable circumstances, (2) results from a company's decision rather than that of an individual employee, (3) is more severe.

Mir et al. (2017) studied the impact of psychological contract violation on supplier switching behavior. The study is leveraged on attribution theory. Psychological contract is established when an individual develops perceived obligations beyond what is stated in the explicit contract (Mir et al., 2017). Psychological contract can also arise in the case of written contracts when a person interprets them differently. Breach of psychological contract occurs when it goes unfulfilled, leading to an emotional sense of violation (Morrison and Robinson, 1997). Intuitively, a buyer may not switch the supplier in case of a supplier breach due to uncontrollable circumstances.

On the contrary, if the buyer perceives the action to be controllable, the buyer may switch suppliers. Hence, Mir et al. (2017) studied the relationship between the attribution (in terms of locus of causality and controllability) and buyer's behavior to switch suppliers. Attribution theory predicts that the buyer assigns more significant blame to the supplier as the severity of damages caused by breach increases (Tennen and Affleck, 1990). The authors studied this relation between the severity of breach (major or minor) and supplier switching by the buyers. They also examined the association between the timing of breach (early vs. late) and supplier switching. They found that the attribution and severity of the breach affect supplier switching, but the breach timing does not. They further explored whether psychological contract violation mediates the relationship (a) between attribution and switching behavior, (b) between severity and switching behavior, and (c) between timing and switching behavior. They found that the psychological contract violation mediates the relationship between attribution and switching behavior 


\section{Singh et al.}

only.

\section{-Social Network Analysis}

Social network analysis (SNA) has roots in sociology and applications in various fields ranging from anthropology and social psychology to chemistry and computer science. Social network analysis is a methodology for describing and analyzing the interrelationships of the nodes within a network. These nodes can represent individuals, individuals within an organization, or organizations within a more extensive network (Carter et al., 2007). The relationships can represent friendship, liking, communication, or exchanging goods (Scott, 2017).

There are various metrics of SNA in terms of network connections, distributions, and segmentation. Mutuality (reciprocity) is the extent to which two actors reciprocate each other's friendship or other interaction (Kadushin, 2012). Centrality helps quantify a particular node's importance (influence) within a network (Hanneman and Riddle, 2011). Betweenness centrality is a measure of centrality based on the shortest path. Closeness centrality quantifies how close a particular node is to all other nodes (i.e., reciprocal of farness). Structural holes imply the absence of ties between two parts of a network. The cohesion of a network is the degree to which nodes are directly connected (Hanneman and Riddle, 2011).

Considering these SNA metrics and other metrics, Borgatti and Li (2009) defined some analogies between SNA and the supply chain. For instance, given a network of supply ties, a firm's measure of high betweenness depends upon the extent to which all of the shortest chains from the first producer to the end consumers pass through that firm. Such a firm is structurally essential to the economy because it will affect other firms (Borgatti and Li, 2009). Similarly, structural holes in a supply network also play a significant role. The more structural holes in the network, the more non-redundant information is available (Choi and Wu, 2009). This can eventually help in the enhanced performance of the supply chain. Choi and Wu further examined the buyer-supplier-supplier triad instead of the buyersupplier dyad in their study. By applying the concept of structural holes, they explored the three-way interactions in the triad.

\section{Other Variables}

\section{-Compliance}

Compliance is a social influence in which a person responds favorably to a request made by others. The request can be explicit or implicit. Compliance communicates a sense of involvement and a desire to maintain relational ties (Etzioni, 1975). In the context of the buyer-supplier relationship, buyer compliance is the reception given by the buyer to a request made by a supplier for relationship continu- 
ance, despite potential costs incurred by the buyer when agreeing to such a request (Gassenheimer and Calantone, 1994). Hung et al. (2009) determined the factors that can positively or negatively affect compliance while controlling other variables in a buyer-supplier relationship. They found that teamwork, humility, and expression are significantly and negatively correlated with compliance behavior, whereas considerateness positively correlates with compliance behavior. They could not find empathy and compassion to be significant factors.

\section{-Social Preference}

In social psychology, social preference refers to the intrinsic concerns for the other's welfare, reciprocating in a positive relationship, as well as the intrinsic desires for a higher relative payoff compared with the others when the status is salient. Research implies that people have emotionally based social goals because those involved in social interactions pursue reciprocity, status, and group identity as the ends in themselves (Camerer, 1999; Frank, 1988). Loch and Wu (2008) examined the influence of social preferences on supply chain transactions. In their experiments, it was found that social preferences influence supply chain contracting situations. Social preferences also play a significant role in influencing the performance of supply chain transactions. A positive relationship fosters mutually beneficial actions from both the players, while status-seeking induces more competitive behavior by both players and decreases performance and efficiency.

\section{Social Psychology and Supply Chain Management}

The increased attention of organizational researchers on supply chain management (SCM) over the last couple of decades has also uncovered the breadth and the complexity of SCM. Being that supply chains involve interactions between human beings, one is bound to experience challenges. Tang et al., (2006) identified two major types of risks that exist in supply chains namely: disruption and operation risks. Operation risks are mainly uncertainties that are inherent within the supply chain and that are inevitable. On the other hand, disruption risks are those that are triggered by an interruption of normal operations of supply chain. Disruption risks often result in major loses even when the event in question is of low frequency. Ruel et al. (2019) argued that a contributing factor for the increased vulnerability within supply chains is the emergence of a trend among supply chain managers to try and reduce their supply base while at the same time trying to strengthen their relationship with suppliers in the reduced supply base. It is essential to note that with a reduced number of suppliers, the firm loses its ability to switch to contingency suppliers when need arises. Given the increase in vulnerability caused by managers' decision to reduce their supply base, the study of social psychology is imperative in helping managers make better decisions that will serve their organizations better. 


\section{Singh et al.}

\section{SCM Levels and Human Interaction}

There are three levels in supply chains: strategic, tactical, and operational. According to Adobor (2019), the company management is tasked with making important strategic decisions that affect the entire organization. Decisions at this level are made with the organization's corporate strategy in mind. It is essential to note that at this level, there are a number of supply chain processes such as customers, product development, logistics, vendors, and manufacturing. While the strategic level takes care of the decisions that affect the organizations' future in the long-term, the tactical level deals with the short-term decision making. Manufacturing decisions are made at the tactical level with the aim of ensuring that products are made with minimized costs while at the same time ensuring that the product maintains its quality. The tactical level decisions are essential in ensuring risk is minimized and costs are controlled. The operation level is what people come into contact with most of the time since this is the level that affects the organizations' day-to-day management, decision-making and planning (Salam et al., 2016).

The interaction of human beings within these levels are critical as they may either make or break the organization. For instance, at the strategic level, if management fails to reach an agreement on decisions, they may end up hurting the organizations' profitability. At the tactical level, failure to make effective decisions regarding cost control could also affect the organization's profitability. Thus, understanding the role played by the people involved on various level will go a long way in shedding light on how psychology affects the organizations performance, efficiency, and decision-making.

\section{METHODOLOGY}

The present study utilized a mapping technique to review social psychology and supply chain literature systematically. This review aims to investigate how human interactions among several supply chains can influence the efficiency, performance, and decisions within a supply chain network. The systematic review approach utilized in this study consists of various phases (1) source identification, (2) source selection, (3) source evaluation, and (4) data analysis. A similar approach has been extensively utilized in the examined literature (La Londe, 2002; Morrison and Robinson, 1997; Tejpal et al., 2013).

\section{-Source Identification}

Before conducting a literature search, it is explicitly essential to define the criteria to be followed. Therefore, a primary requisite was that the literature matches the definition of social psychology and SCM provided in literature review. Table 1 (see Appendix-I) provides further inclusion criteria, including quality-related criteria, to ensure high-quality literature, and content-related criteria to determine 
sources relevant to the research question.

It was decided to follow an inclusive method without limiting the search to a predefined set of journals and other articles that meet the criteria to portray publication outlets' diversity that typically relates to the current study. Three databases were utilized to extract data: Google Scholar, Science Direct Metadata, and ACM digital library, because they are authentic and reliable, which adds more value to the current study.

Search strings blended with a semi-automated citation and eventually a manual crosscheck for all the sources. After applying the inclusion criteria, a key sample of 10 relevant sources was utilized to optimize the search string iteratively. The study wanted to have many articles from this sample while eliminating any irrelevant sources. The search strings were optimized and constructed by determining the central themes and keywords such as behavioral SCM, social psychology, human behavior, trust, power, attribution theory, social network analysis, and potential synonyms in SCM and social psychology by examining publication titles, keywords, abstracts, and respective descriptors of each source from the primary sample.

\section{-Source Selection}

Source selection refers to the process of identifying literature that would be used during the study. The selection process began after applying the inclusion criteria; 230 articles passed the criteria. Subsequently, we used a coding sheet to assess the sources while adhering to the quality-related and content-related criteria to minimize bias that could have arisen in the process. These researchers examined the abstract of each sample, and when they could draw unclear decisions from it, they rejected the entire text. Out of the sample, 52 articles were selected, and the search strategy was verified through manual crosschecking starting in publication dates order.

Peer-reviewed journals were selected from the Journal of Marketing Research, Journal of Operations Management, Journal of SCM, and Journal of Retailing. Books and other sources were selected from prestigious publishers such as Sage, Oxford, Emerald, and Springer. These articles formed the sample of this study. Several areas such as social psychology, supply chain management, operations, organizational behavior have been searched, and thought-provoking articles were selected.

\section{-Source Evaluation}

Source evaluation entails deductive and inductive grouping of the sources using predefined criteria. This section thus addresses the sources based on the bibliometric features. The sources used have different publication dates between 1957 and 2020, as depicted below. According to frequency analysis of these publications, it can be noted that SCM and social psychology are not new concepts 


\section{Singh et al.}

in literature. However, they gained momentum from 2008, as depicted in the numbers of sources. Besides, using recent data improve the quality of the current study as they provide updated information.

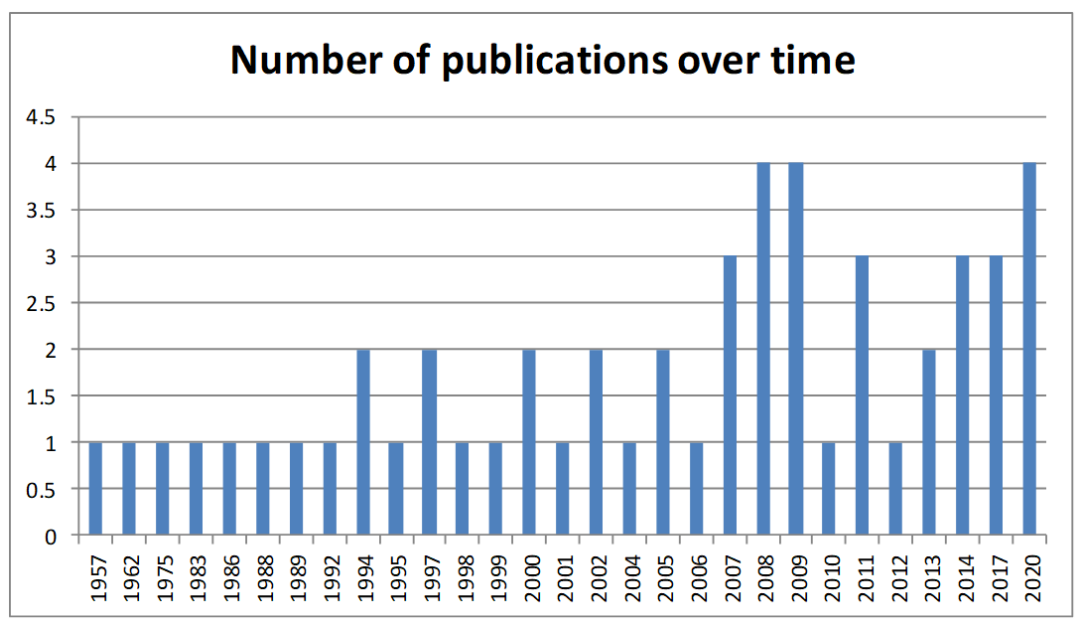

Source: Authors' Presentation

Figure 1. Number of Publications Over Time

Based on the kind of sources, the current study includes a variety of sources from peer-reviewed articles as tabulated in Table 2.

\section{-Analysis}

According to Denyer and Tranfield (2009), an analysis should be thoroughly aligned with the review purpose. Therefore, the initial research objectives sought to determine how human interactions among several supply chains can influence the efficiency, performance, and decisions within a supply chain network. Denyer and Tranfield (2009) suggest that beginning with a transparent examination of the chronological involvement of the field of study offers essential background detail for subsequent analysis. The selected articles were compared to typical SCM and social psychology frameworks to comprehend the current state of research and map out this study's structure. The research team developed a two-dimensional framework following an iterative process. First, they derived overarching SCM and social psychology research categories from seminal literature. Second, each team member was requested to group the selected sources based on research categories. Arguments about the classifications were judged iteratively to facilitate framework refinement until the team reached a consensus.

Research method analysis was done according to predefined categories, including empirical, non- 


\begin{tabular}{lcc}
\hline Peer Reviewed Journals & Number of Articles & Share \\
\hline Journal of Marketing Research & 6 & $11.5 \%$ \\
Journal of Operations Management & 7 & $13.5 \%$ \\
Journal of Supply Chain Management & 11 & $21.1 \%$ \\
Journal of Business Logistics & 6 & $11.5 \%$ \\
Journal of Retailing & 2 & $3.8 \%$ \\
National Academy of Sciences & 3 & $5.8 \%$ \\
Business Process Management Journal & 2 & $3.8 \%$ \\
Journal of Business and Management & 3 & $5.8 \%$ \\
Journal of Management Science & 2 & $3.8 \%$ \\
Others & 10 & $19.2 \%$ \\
\hline
\end{tabular}

Source: Authors' Presentation

Table 2. Number of Related Publications by Journals

empirical, and mixed methods, as presented in Table 3, which were derived from previous SCM and social psychology reviews (Emerson, 1962; La Londe, 2002; Morrison and Robinson, 1997; Tejpal et al., 2013). Research topics were examined in an explorative way. The topics were first classified in an unstructured way and then grouped into various categories. Leading academics examined empirical, non-empirical, and mixed methods papers published by international publisher such as Taylor \& Francis, Inderscience, Emerald publishing, and Sage. Further, journals were selected from Scopus and Web of Science databases then revised the topics in both research areas until a multiple exclusive and consistent image was developed, as shown in Table 3. Detailed analysis was done to determine the existing research gaps in the light of the descriptive results.

\section{RESULTS AND DISCUSSION}

This article revolves around understanding various factors related to social psychology and their influence on supply chain. Trust amongst the players within a supply chain network is one of the most crucial factors influencing the supply chain's performance. It helps in information sharing between or amongst the members of supply and simultaneously decreases the transaction costs for scrutinizing activities (Kwon and Suh, 2004), hence, the performance of the supply chain increases. Some studies also suggest the factors that can influence the level of trust, which can be unpredictable behavior 


\section{Singh et al.}

(Kwon and Suh, 2005), knowledge, level of risk, and risk tolerance level (Laeequddin and Sardana, 2010).

\begin{tabular}{ll}
\hline Type & \multicolumn{1}{c}{ Research Method } \\
\hline Empirical & Case studies involving interviews, direct observations, and document analysis \\
& Archival studies \\
& Survey and statistical sampling \\
& Experiments \\
Non-empirical & Conceptual \\
& Modeling \\
& Simulation \\
\cline { 2 - 2 } Other & Mixed methods \\
\hline
\end{tabular}

Source: Authors' Presentation

Table 3. Research Methods used in Sample Journals'Articles

Power may negatively influence the relationship between the supply chain partners and decrease the supply chain's performance (Nyaga et al., 2013; Pulles et al., 2014). On the other hand, customer power increases the supplier's relationship commitment (Zhao et al., 2008). Moreover, Ireland and Webb (2007) claimed that an optimal balance of trust and power could result in cultural competitiveness in a strategic supply chain, improving its efficiency.

How a customer attributes the events in supply chain disruption (Hartmann and Moeller, 2014) or psychological contract breach also influences the relationship between buyer and supplier, leading to supplier switching (Mir et al., 2017).

Since the supply chain network needs not be linear, social network analysis (SNA) can be helpful to understand the links and relationships between various nodes (people) of the network (Borgatti and Li, 2009). The concept of structural holes from SNA was also adopted by Choi and Wu (2009) to examine the performance of the supply chain in the presence of structural holes.

Hung et al. (2009) found that teamwork, humility, and expression can decrease compliance behavior, whereas considerateness can increase compliance behavior within a buyer-supplier relationship. From the Social preferences lens, a positive relationship helps in the growth of mutually beneficial actions from both the partners, while status-seeking induces the competitive behavior of 
both players and decreases performance and efficiency (Loch and Wu, 2008).

Hence, as the literature suggests that the people's behavior influences the performance and efficiency of the supply chain. This can be due to trust (or lack of trust), power, attribution of disruption or unsustainable activities within a chain by the consumer, effect of centrality, structural holes, and cohesion in the network, or compliance and social preferences in the relationships of various players.

\section{CONCLUSION}

Human behavior influences the performance, efficiency, and many decisions in a supply chain. This article gives insights into how several social psychology variables are related to the supply chain. Effect of trust, power, and combination of trust and power was emphasized on the buyer-supplier relationships and supply chain performance. Theoretically, this study contributes to the discussion on the impact of social psychology on supply chains and businesses as a whole. The managerial implication is that supply chain managers are able to understand how their interactions impact the wellbeing and profitability of their organizations. Similarly, how the customer attributes any kind of mishap also affects the relationships and the decisions. It also includes how the customer attributes the breach of the psychological contract. Many researchers have used social network analysis (SNA) to investigate complex relationships between many players within a supply chain network. The influence of compliance and social preferences has been examined in buyer-supplier relation and partners' relation, respectively.

\section{IMPLICATIONS}

Supply chain managers can use the findings of this research to determine how they can increase level of trust with clients throughout the supply process. The increased trust would enhance supply chain collaboration, collaborative advantage, and positive performance. Trust ensures the integrity of supply chains since customers have to build trust in the suppliers that their goods will be delivered timely, upon the agreed price, and in good condition. Equally, the trust would improve how buyers treat suppliers with respect and complete payments based on the agreed terms. However, the exercise of extreme power levels undermines the performance of supply chains since it reduces collaboration and commitment between different stakeholders in meeting customers' demands.

The findings of this study also confirm the attribution theory. Attribution theory views individuals as logical information processors who attempt to make sense of their environment by attributing or relating causes to occurrences. Similarly, the study supports this theory in that the suppliers and cons- 


\section{Singh et al.}

umers seek to comprehend what causes performance, efficiency, and decisions of supply chains and determines who is responsible in SCM.

\section{LIMITATIONS AND FUTURE DIRECTIONS}

While attempting to examine the influence of human behavior in the supply chain, the present study did not consider many other dimensions of the supply chain. For instance, the authors consider the movement of goods and services only in one direction, from producer to consumer. Reverse logistics deals with the movement of goods in the opposite direction, from the consumer to the supplier. The customer has likely gone through unpleasant experiences. Hence, the concept of logistics and reverse logistics should be considered different while considering the influence of human behavior, therefore, should be studied separately.

Most empirical studies relied on data collected from only one geographical region (Benton and Maloni, 2005; Zhao et al., 2008). In the future, it will be interesting to see if findings are consistent across other geographical regions.

Furthermore, the field of social psychology in SCM continues to mature. Thus, future researchers may consider integrating other aspects of social psychology such as self-concept, social influence, prejudice and discrimination, and interpersonal processes to determine how they influence human behavior in SCM.

In this study, the researchers encountered a significant challenge in categorizing sources and data since they contradicted each other. When a contradiction occurred, no action would be possible until it was resolved. Future researchers may apply ATLAS.ti analysis software which could solve such contradictions in qualitative research as recommended by Woolf (2014). Besides, researchers can improve the validity and reliability of data by applying triangulation which is an analytical strategy that minimizes researchers' potential to draw erroneous conclusions when they over-depend on one technique or data set.

\section{REFERENCES}

Adobor, H. (2019). Supply chain resilience: A multi-level framework. International Journal of Logistics Research and Applications, 22(6): 533-556. https://doi.org/10.1080/13675567.2018.1551483

Anderson, E., \& Weitz, B. (1992). The use of pledges to build and sustain commitment in distribution channels. Journal of Marketing Research, 29(1): 18-34. https://doi.org/10.1177/002224379202900103

Bendoly, E., Donohue, K., \& Schultz, K. L. (2006). Behavior in operations management: Assessing recent findings and revisiting old assumptions. Journal of Operations Management, 24(6): 737-752. https://doi.org/10.1016/j.jom.2005.10.001

Benton, W. C., \& Maloni, M. (2005). The influence of power driven buyer/seller relationships on supply chain satisfaction. Journal of Operations Management, 23(1): 1-22. https://doi.org/10.1016/j.jom.2004.09.002

Borgatti, S. P., \& Li, X. (2009). On social network analysis in a supply chain context. Journal of Supply Chain Management, 45(2): 5-22. https://doi.org/10.1111/j.1745-493x.2009.03166.x

Bowersox, D. J., Closs, D. J., \& Stank, T. P. (2000). Ten mega-trends that will revolutionize supply chain logistics. Journal of Business Logistics, 21(2): 7-32. https://doi.org/10.5325/transportationj.54.1.0007 
Brown, J. R., Lusch, R. F., \& Nicholson, C. Y. (1995). Power and relationship commitment: Their impact on marketing channel member performance. Journal of Retailing, 71(4): 363-392. https://doi.org/10.1016/0022-4359(95)90019-5

Bruccoleri, M., Cannella, S., \& La Porta, G. (2014). Inventory record inaccuracy in supply chains: The role of workers' behavior. International Journal of Physical Distribution and Logistics Management, 44(10): 796-819. https://doi.org/10.1108/ijpdlm09-2013-0240

Camerer, C. (1999). Behavioral economics: Reunifying psychology and economics. Proceedings of the National Academy of Sciences, 96(19): 10575-10577. https://doi.org/10.1073/pnas.96.19.10575

Carter, C. R., Ellram, L. M., \& Tate, W. (2007). The use of social network analysis in logistics research. Journal of Business Logistics, 28(1): 137-168. https://doi.org/10.1002/j.2158-1592.2007.tb00235.x

Cheng, J. H., Yeh, C. H., \& Tu, C. W. (2008). Trust and knowledge sharing in green supply chains. Supply Chain Management: An International Journal, 13(4): 283-295. https://doi.org/10.1108/13598540810882170

Choi, T. Y., \& Wu, Z. (2009). Triads in supply networks: Theorizing buyer-supplier- supplier relationships. Journal of Supply Chain Management, 45(1): 8-25. https://doi.org/10.1111/j.1745-493x.2009.03151.x

Cooper, M.C., Lambert, D.M., \& Pagh, J.D. (1997). Supply chain management: More than a new name for logistics. The International Journal of Logistics Management, 8(1): 1-14. https://doi.org/10.1108/09574099710805556

Crook, T. R., \& Combs, J. G. (2007). Sources and consequences of bargaining power in supply chains. Journal of Operations Management, 25(2): 546-555. https://doi.org/10.1016/j.jom.2006.05.008

Denyer, D., \& Tranfield, D. (2009). The SAGE Handbook of producing a Systematic Review. Organizational Research Methods, 9(2): 671-689. https://doi.org/10.1177/1094428105284944

Donohue, K., \& Siemsen, E. (2011). Behavioral operations: Applications in supply chain management. Wiley encyclopedia of operations research and management science. https://doi.org/10.1002/9780470400531.eorms0103

Doyle, J., Ojiako, U., Marshall, A., Dawson, I., \& Brito, M. (2020). The anchoring heuristic and overconfidence bias among frontline employees in supply chain organizations. Production Planning and Control, 1-18. https://doi.org/10.1080/09537287.2020.1744042

Emerson, R. M. (1962). Power-dependence relations. American Sociological Review, 271), $31-41$. https://doi.org/10.2307/2089716

Etzioni, A. (1975). Review of A Comparative Analysis of Complex Organizations. Political Science Quarterly, 91(2), $341-342$. https://doi.org/10.2307/2148419

Frank, R. H. (1988). Passions within reason: The strategic role of the emotions. WW Norton \& Co. https://doi.org/10.2307/2233985

Gassenheimer, J. B., \& Calantone, R. J. (1994). Managing economic dependence and relational activities within a competitive channel environment. Journal of Business Research, 29(3): 189-197. https://doi.org/10.1016/0148-2963(94)90003-5

Ghosh, A., \& Fedorowicz, J. (2008). The role of trust in supply chain governance. Business Process Management Journal, 14(4): 453-470. https://doi.org/10.1108/14637150810888019

Goodman, L. E., \& Dion, P. A. (2001). The determinants of commitment in the distributor- manufacturer relationship. Industrial Marketing Management, 30(3): 287-300. https://doi.org/10.1016/s0019-8501(99)00092-9

Hanneman, R., \& Riddle, M. (2011). The SAGE Handbook of Social Network Analysis. Concepts and Measures for Basic Network Analysis, 9(2): 364-367. https://doi.org/10.4135/9781446294413.n24

Hartmann, J., \& Moeller, S. (2014). Chain liability in multi-tier supply chains? Responsibility attributions for unsustainable supplier behavior. Journal of Operations Management, 32(5): 281-294. https://doi.org/10.1016/j.jom.2014.01.005

Hewege, C., \& Perera, C. (2020). The Impact of Religio-Cultural Institutional Hegemony on Sri Lankan (halal) Supply Chains: Theorising the Interplay between the Certification Body, Social Institutions and the Government. Journal of Muslim Minority Affairs, 40(3): 351-370. https://doi.org/10.1080/13602004.2020.1813987

Hill, J. A., Eckerd, S., Wilson, D., \& Greer, B. (2009). The effect of unethical behavior on trust in a buyer-supplier relationship: The mediating role of psychological contract violation. Journal of Operations Management, 27(4): $281-293$. https://doi.org/10.1016/j.jom.2008.10.002

Hong, J., Guo, P., Chen, M., \& Li, Y. (2020). The adoption of sustainable supply chain management and the role of organisational culture: A Chinese perspective. International Journal of Logistics Research and Applications, 25(5):1-25. https://doi.org/10.1080/13675567.2020.1795094

Hult, G. T., Ketchen, D. J., \& Nichols, E. L. (2002). An examination of cultural competitiveness and order fulfillment cycle time within supply chains. Academy of Management Journal, 45(3): 577-586. https://doi.org/10.5465/3069382

Hung, K. T., Ro, Y. K., \& Tangpong, C. (2009). Agent characteristics and compliance behavior in supply chain disruptions. Journal of Business and Management, 15(1): 51. https://doi.org/10.1016/j.jom.2009.12.001

Ireland, R. D., \& Webb, J. W. (2007). A multi-theoretic perspective on trust and power in strategic supply chains. Journal of Operations Management, 25(2): 482-497. https://doi.org/10.1016/j.jom.2006.05.004

Kadushin, C. (2012). Understanding social networks: Theories, concepts, and findings. Oxford: Oxford University Press. https://doi.org/10.5860/choice.49-6586

Kassin, S., Fein, S., \& Markus, H. R. (2011). Social psychology. Social Behavior and Personality: An InternationalJjournal, 40 (8): 1365-1372. https://doi.org/10.2224/sbp.2012.40.8.1365

Kwon, I. W., \& Suh, T. (2004). Factors affecting the level of trust and commitment in supply chain relationships. Journal of Supply Chain Management, 40(1): 4-14. https://doi.org/10.1111/j.1745-493x.2004.tb00165.x

Kwon, I. W., \& Suh, T. (2005). Trust, commitment and relationships in supply chain management: A path analysis. Supply Chain Management: An international journal, 10(1): 26-33. https://doi.org/10.1108/13598540510578351 


\section{Singh et al.}

La Londe, B., \& Cooper, M. (1989). Partnership in providing customer service: A third-party perspective. Defense Transportation Journal, 4(5): 46-58.

Laeequddin, M., \& Sardana, G. D. (2010). What breaks trust in customer-supplier relationship? Management Decision, 48(3): 353-365. https://doi.org/10.1108/00251741011037738

Loch, C. H., \& Wu, Y. (2008). Social preferences and supply chain performance: An experimental study. Management Science, 54(11): 1835-1849. https://doi.org/10.1287/mnsc.1080.0910

Maloni, M., \& Benton, W. C. (2000). Power influences in the supply chain. Journal of Business Logistics, 21(1): 49-56.

Melnyk, S. A., Closs, D. J., Griffis, S. E., Zobel, C. W., \& Macdonald, J. R. (2014). Understanding supply chain resilience. Supply Chain Management Review, 18(1): 34-41.

Mir, S., Aloysius, J. A., \& Eckerd, S. (2017). Understanding supplier switching behavior: The role of psychological contracts in a competitive setting. Journal of Supply Chain Management, 53(3): 3-18. https://doi.org/10.1111/jscm.12115

Moore, K. R. (1998). Trust and relationship commitment in logistics alliances: A buyer perspective. Journal of Supply Chain Management, 34(4): 24-37. https://doi.org/10.1111/j.1745-493x.1998.tb00039.x

Morgan, R. M., \& Hunt, S. D. (1994). The commitment-trust theory of relationship marketing. Journal of Marketing, 58(3): 2038. https://doi.org/10.2307/1252308

Morrison, E. W., \& Robinson, S. L. (1997). When employees feel betrayed: A model of how psychological contract violation develops. Academy of Management Review, 22(1): 226-256. https://doi.org/10.5465/amr.1997.9707180265

Nyaga, G. N., Lynch, D. F., Marshall, D., \& Ambrose, E. (2013). Power asymmetry, adaptation and collaboration in dyadic relationships involving a powerful partner. Journal of Supply Chain Management, 49(3): 42-65. https://doi.org/10.1111/jscm.12011

Pulles, N. J., Veldman, J., Schiele, H., \& Sierksma, H. (2014). Pressure or pamper? The effects of power and trust dimensions on supplier resource allocation. Journal of Supply Chain Management, 50(3): 16-36. https://doi.org/10.1111/jscm.12049

Ruel, S., Shaaban, S., \& Ducros, M. (2019). Supply chain vulnerability: contributions from an edifying case study. Journal of Enterprise Information Management, 32(2): 214-232. https://doi.org/10.1108/JEIM-05-2018-0086

Reimann, F., \& Ketchen, D. J. (2017). Power in Supply Chain Management. Journal of Supply Chain Management, 53(2): 3-9. https://doi.org/10.1111/jscm.12140

Salam, A., Panahifar, F., \& Byrne, P. J. (2016). Retail supply chain service levels: the role of inventory storage. Journal of Enterprise Information Management, 29(6):887-902. https://doi.org/10.1108/JEIM-01-2015-0008

Schorsch, T., Wallenburg, C. M., \& Wieland, A. (2017). The human factor in SCM: introducing a meta-theory of behavioral supply chain management. International Journal of Physical Distribution and Logistics Management, 47(4): 238262. https://doi.org/10.1108/IJPDLM-10-2015-0268

Scott, J. (2017). SAGE publications. Social network analysis. 9(2): 74-109. https://doi.org/10.4135/9781529716597

Simon, H. A. (1957). Models of man: Social and rational; mathematical essays on rational human behavior in society setting. New York, NY: Wiley.

Tang, L., Jing, K., He, J., \& Stanley, H. E. (2016). Complex interdependent supply chain networks: Cascading failure and robustness. Physica A: Statistical Mechanics and lts Applications, 443, 58-69. https://doi.org/10.1016/j.physa.2015.09.082

Tejpal, G., Garg, R. K., \& Sachdeva, A. (2013). Trust among supply chain partners: A review. Measuring Business Excellence, 17(1): 51-71. https://doi.org/10.1108/13683041311311365

Tennen, H., \& Affleck, G. (1990). Blaming others for threatening events. Psychological Bulletin, 108(2): 209-229. https://doi.org/10.1037/0033-2909.108.2.209

Weiner, B. (1986). An attributional model of motivation. New York: Springer.

Weiner, B. (1992). Human motivation: Metaphors, theories, and research. Sage. https://doi.org/10.1007/978-1-4612-4948-1

Woolf, N. (2014). Analytic strategies and analytic tactics. SAGE publications. https://doi. org/10.14279/depositonce-4848.

Zhao, X., Huo, B., Flynn, B. B., \& Yeung, J. H. (2008). The impact of power and relationship commitment on the integration between manufacturers and customers in a supply chain. Journal of Operations Management, 26(3): 368-388. 


\begin{tabular}{|c|c|c|}
\hline & Inclusion Criteria & Rationale \\
\hline Quality-related criteria & $\begin{array}{l}\text { The article is published in a peer- } \\
\text { reviewed journal or by verified } \\
\text { publishers such as Sage publishers, } \\
\text { Springer and Oxford. }\end{array}$ & $\begin{array}{l}\text { This research intends to cover } \\
\text { various contributions in the social } \\
\text { psychology and SCM fields while } \\
\text { ensuring high-quality levels. Only } \\
\text { peer-reviewed sources can reliably } \\
\text { provide insight into the current } \\
\text { research state and concurrently } \\
\text { ensure the high-quality level. }\end{array}$ \\
\hline \multirow[t]{3}{*}{ Content-related criteria } & $\begin{array}{l}\text { The article matches the definitions } \\
\text { of SCM }\end{array}$ & $\begin{array}{l}\text { This research focuses on social } \\
\text { psychology research in SCM but } \\
\text { does not explore other application } \\
\text { fields. }\end{array}$ \\
\hline & $\begin{array}{l}\text { The article matches the definition } \\
\text { of social psychology }\end{array}$ & $\begin{array}{l}\text { This study focuses on the various } \\
\text { aspects of social psychology with } \\
\text { their relation to SCM. }\end{array}$ \\
\hline & $\begin{array}{l}\text { The article makes a substantial } \\
\text { theoretical contribution }\end{array}$ & $\begin{array}{l}\text { Only original theoretical } \\
\text { contributions provide insights on } \\
\text { the present state of study in social } \\
\text { psychology and SCM }\end{array}$ \\
\hline
\end{tabular}

